\title{
Review on the study of Nonlinear Optics of Iridium Metal Organic Complex
}

\author{
Lu Li, Huajian Duan, Jun Qian* \\ School of Chemistry and Chemical Engineering, Jiangsu University, Zhenjiang, China \\ Email: ^junqian820314@163.com
}

How to cite this paper: Li, L., Duan, H.J. and Qian, J. (2021) Review on the study of Nonlinear Optics of Iridium Metal Organic Complex. Journal of Materials Science and Chemical Engineering, 9, 24-42. https://doi.org/10.4236/msce.2021.92003

Received: January 6, 2021

Accepted: February 23, 2021

Published: February 26, 2021

Copyright $\odot 2021$ by author(s) and Scientific Research Publishing Inc. This work is licensed under the Creative Commons Attribution International License (CC BY 4.0).

http://creativecommons.org/licenses/by/4.0/

(c) (i) Open Access

\begin{abstract}
Nonlinear optical materials are one of the key research objects in the field of optics, which mainly research the nonlinear effects of the interaction between luminesce and matter. Compared with inorganic nonlinear optical materials, organic nonlinear materials have outstanding advantages: strong adaptability, high flexibility, low cost, easy modification and damage resistance. In this review, the electric field induced second harmonic generation (EFISH) experimental technology is used to measure and research the nonlinearity of iridium metal complexes. And because of its structural diversity, people can design molecules according to their needs to get the best nonlinear optical response. Organic molecules with large nonlinear coefficients should have the following characteristics: asymmetric charge distribution, the delocalized nature of $\pi$ electrons, and easy polarization by external electric fields, and a large $\pi$ conjugated system. In recent years, metal organic compounds have become a leader in the field of optics, mainly because of their very good nonlinear optical properties. In the future, people will do more investigation on the nonlinearity of metal organic complexes. Researchers have shown great interest in iridium metal organic complexes due in particular to their attractive stability and nonlinear activity. This review mainly studies the nonlinear principle, performance test and Measurement of nonlinearity of iridium metal complexes. The nonlinear properties of other metal-metal organic complexes will not be discussed.
\end{abstract}

\section{Keywords}

Nonlinear Optics, EFISH, Iridium Complexes

\section{Introduction}

The nonlinear optical effects of urea picric acid dinitroaniline and other organic compounds were discovered at the beginning of the study of nonlinear optical materials. Since organic molecules with large non-localized $\pi$-conjugated elec- 
tron systems exhibit strong photoelectric coupling characteristics, they can obtain high response values and relatively large optical coefficients. After the 1980s, organic nonlinear optical materials developed rapidly. Compared with inorganic materials, organic materials have the advantages of high nonlinear optical coefficient, fast response, easy modification, damage resistance, easy processing, and strong molecular variability [1]. At present, the discovery or synthetic of organic nonlinear optical materials is a research hotspot, including various organic low-molecular nonlinear optical materials, high polymer nonlinear optical materials, metal organic complex nonlinear optical materials, etc. Metallocene complexes, metal carbonyl complexes, metal olefin organic complexes, metal polyacetylene polymers, metal porphyrin organic complexes, metal phthalocyanine organic complexes, metal iridium organic complexes and other complexes Type nonlinear optical materials, included. Iridium (III) complexes will undoubtedly become a hotspot in the research of second-order nonlinear optical materials because of their six-coordination, multiple valence states, diverse coordination forms and excellent performance [2]. In 1986, C. C. Frazier et al., First reported the second harmonic effect of metal organic compounds. Since then, some non-linear effects of metal organic compounds had been discovered one after another. The molecular configuration has a direct effect on the nonlinear optical properties and color of the metal-organic complex. Due to the diversity of ligand metals, metal-organic compounds also have various structures, which have more advantages than nonlinear optical materials composed of simple organic molecules. Because metal atoms have different $\mathrm{d}$ or f electron numbers, different oxidation states and coordination numbers, they can form different three-dimensional structures, resulting in unique optoelectronic properties. For example, the redox change of the central metal may lead to a larger molecular hyperpolarizability; the central metal can also become a chiral center, and a non-centrosymmetric crystal can be obtained after splitting; the introduction of metal atoms can combine magnetic and electrical properties with optical properties to produce magneto-optical and electro-optical effects. In addition, metal-organic complexes have more absorption bands, and there are photons transition from metal to ligand and from ligand to metal, with larger ground state dipole moment and polarizability, and energy between ground state and excited state. The level difference is small, which is beneficial to improve the photoelectric response speed of the material. The design and synthesis of ligands with novel structures will be beneficial to the further development of complex research. Numerous reviews on non-linear review articles with rhodium, zinc and other metal organic complexes have been reported. Whereas, few reviews on iridium metal organic complexes are discussed [3]. This review mainly studies the nonlinear optical principle, performance test and application of iridium metal complexes.

\section{Principles of Second-Order Nonlinear Optics}

The electric polarization $P(r, t)$ is a prerequisite for the nonlinear optical ef- 
fect. Under the laser high-intensity photoelectric field $E(r, t)$, the medium will produce a nonlinear electric polarization intensity $P^{N L}(r, t)$, which is a power relationship with the incident photoelectric field [4] describes the medium electric polarization intensity $P(r, t)$. The most important physical quantity of and optical field intensity $E(r, t)$ is the optical polarizability. Therefore, the study of nonlinear optical susceptibility is of great significance to the study of nonlinear optical effects [4]. Under the action of an electric field, the positive and negative charge centers of the atoms migrate, that is, polarization occurs, resulting in an induced dipole moment. Before the appearance of laser, the induced dipole moment was only related to the first order term of the applied electric field intensity $E$.

$$
p=\alpha E
$$

$\alpha$ is the linear polarizability of a molecule or atom.

Laser is a light source with high intensity, excellent monochromatism and coherence. The polarization intensity of the medium under such strong light is no longer a simple linear relation with the incident light intensity, but is related to the higher order term of the light field intensity.

At this point, the polarized $\mathrm{pM}$ of the molecule can be expressed as:

$$
p M=\alpha E+\beta E^{2}+\gamma E^{3}+\cdots
$$

$\beta$ is the first-order molecular hyperpolarizability (second-order effect), and $\gamma$ is the second-order molecular hyperpolarizability (third-order effect). The stronger of incident light intensity will lead to a stronger nonlinear effect. Molecules have non-central symmetry, which is one of the indispensable conditions for optical materials to have nonlinearity, so $\beta$ must not be zero.

If the incident field is an alternating electric field, then:

$$
E=E_{0} \cos (\omega t)
$$

Substituting Equation (3) into Equation (2), and taking into account the vector properties of electric field and polarization [5], Equation (2) can be written as:

$$
P_{M}=\sum_{j} \alpha_{i j} E_{j}+\frac{1}{2} \sum_{j k} \beta_{i j k} E_{j} E_{k}+\frac{1}{6} \sum_{j k l} \gamma_{i j k l} E_{j} E_{k} E_{l}+\cdots
$$

The optical susceptibility is only briefly introduced, and more details are in the literature [6]-[15].

Obtained from the classic two-level model theory: $\beta=\beta_{1}+\beta_{\mathrm{CT}}$, where $\beta_{1}$ reflects the interaction energy of each substituent with the $\pi$ skeleton; And $\beta_{\mathrm{CT}}$ shows the contribution of charge transfer, that is, considering the interaction between the ground state and the excited state, its expression:

$$
\beta_{C T}=\frac{e^{2}}{m \hbar^{3}} \frac{\omega_{n g} f_{n g} \Delta \mu_{n g}}{\left(\omega_{n g}^{2}-4 \omega^{2}\right)\left(\omega_{n g}^{2}-\omega^{2}\right)}
$$

where $f_{n g}$ is the oscillator strength of the transition between the ground state and the excited state, and $\Delta \mu_{n g}$ is the difference between the electric dipole 
moments of the ground state and the excited state. The comparison between experimental test results and calculations shows that the $\beta_{C T}$ term can explain the nonlinear response of disubstituted polyolefins and isomers of nitroaniline. From this equation, Equation (5) shows that in order to have a high $\beta_{C T}$ value, a compound must have charge-transfer transitions at low energy and huge $\Delta \mu_{\mathrm{ng}}$ and $f_{\mathrm{ng}}$ values. The oscillator strength of the transition should be increased as much as possible and the difference between the excited state and the ground state dipole moment should be increased. Therefore, the most effective method is to increase the electron activity of the donor and acceptor substituents.

By calculating the nonlinear optical susceptibility, the nonlinear optical properties of a series of organic molecules synthesized in the laboratory are theoretically calculated and predicted. The relationship between molecular structure and optical properties is discussed. A large number of studies have verified that the value $\beta$ of the molecular system is extremely sensitive to the geometric structure characteristics of the molecule, so it is necessary to determine the geometric structure of the molecule in order to calculate the nonlinear response of the molecular system.

The results from Table 1 show that for most organic compounds and organic metal molecular materials, the contribution of the three-level term is approximately proportional to that of the two-level term. Herein, it is not necessary to consider the contribution of the three-level term everywhere, and the contribution of the charge transfer state to the two-level term can be used to qualitatively understand the nonlinear optical properties of the material. In the theory of quantum chemistry, another relatively important method is the molecular orbital image, that is, a molecule with many atoms or groups can be described by molecular orbital composed of atomic orbital and so on. The transition between orbitals is usually described by the mixing coefficient of the configuration interaction. The typical chromophore structure coefficient is listed in the above table. A transition between the orbital configurations describes the state-state transition of the molecule quite accurately. For some molecules, the primary excitation occurs between the highest occupied molecular orbital (HOMO) and the lowest unoccupied molecular orbital (LOMO). Table 1 can be used as an example to illustrate this transition.

\section{Measurement of Nonlinearity of Iridium Metal Complexes}

Optical susceptibility is one of the important indicators for studying the quality of nonlinear optical materials. The simplest and most direct method to measure the optical susceptibility of materials is the electric field-induced second harmonic generation (EFISH) experimental technique [1] [5] [16]-[22], this technology illustrates the relationship between structure and performance.

Figure 1 is a diagram of the EFISH experimental setup. The beam is polarized by the Glan prism and enters the sample cell after passing through the diaphragm and $1.06 \mu \mathrm{m}$ color filter. The diameter of the light spot is about $0.5 \mathrm{~mm}$. 
Table 1. The relative contribution of the two-level term $\left(\beta_{\mathrm{vec}, 2}\right)$ and the three-level term $\left(\beta_{\mathrm{vec}, 3}\right)$ of some representative chromophores to the hyperpolarizability [23].

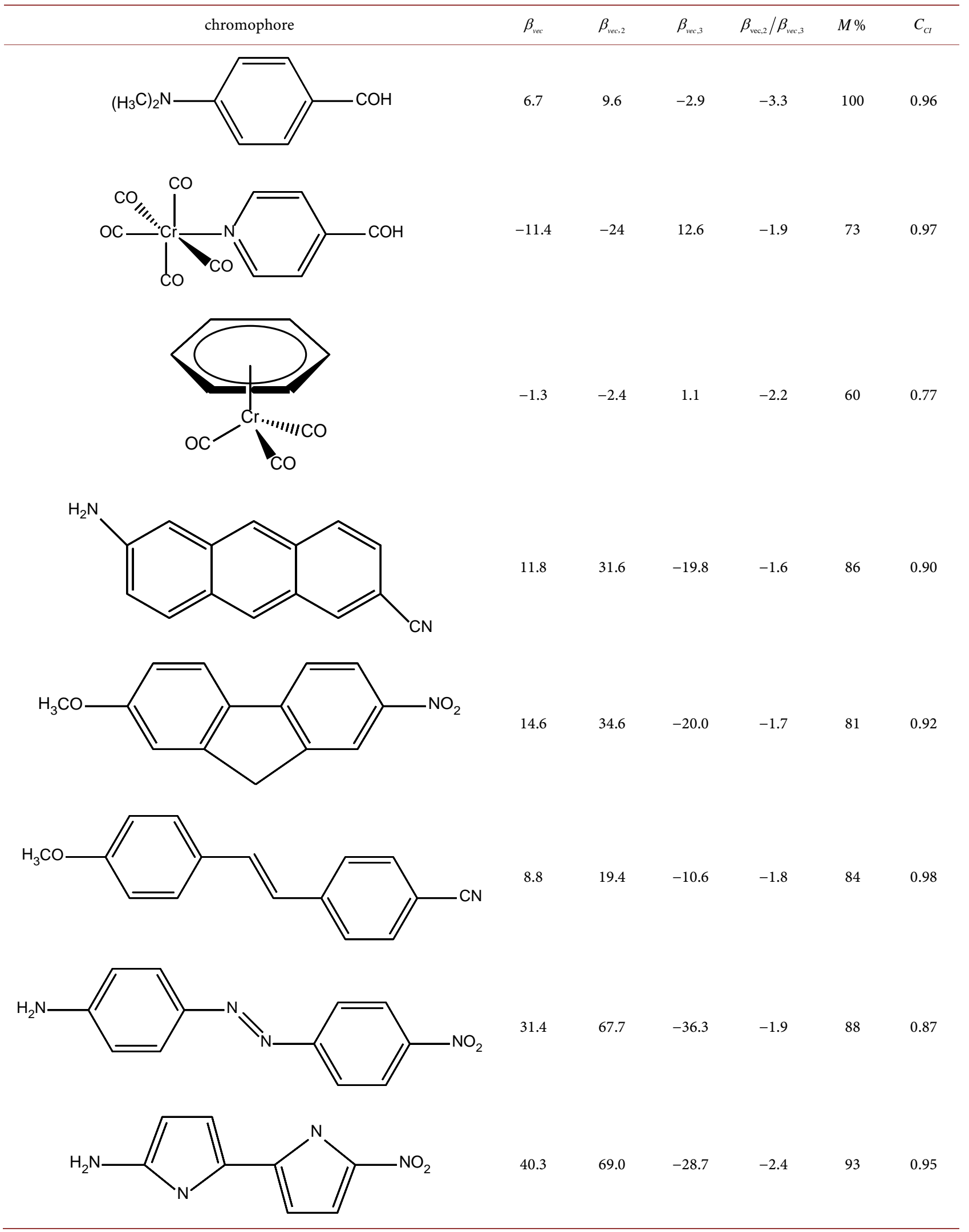




\section{Continued}

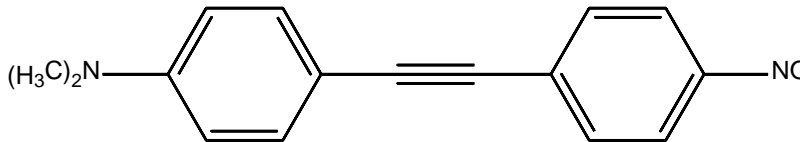

77.9

$-47.5$

$-1.6$

80

0.80
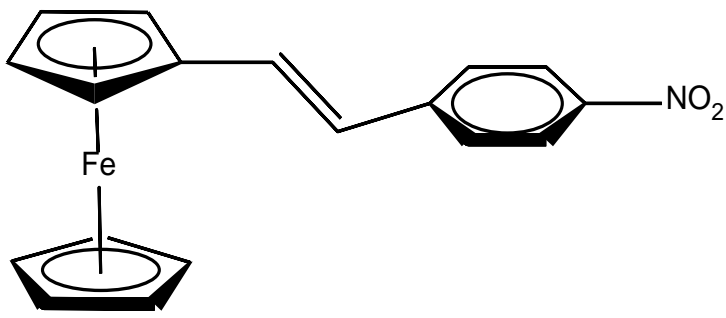

30.8

71.8

$-41.0$

$-1.8$

76

0.77

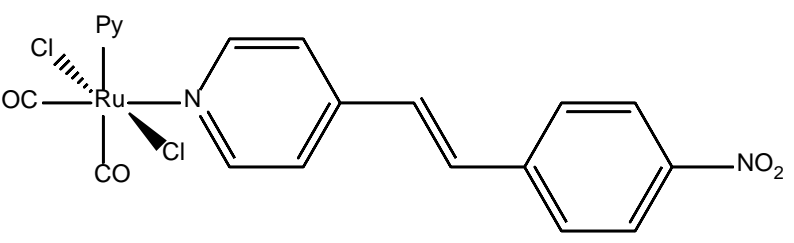

$-12.4$

$-24$

11.6

$-2.1$

65

0.85

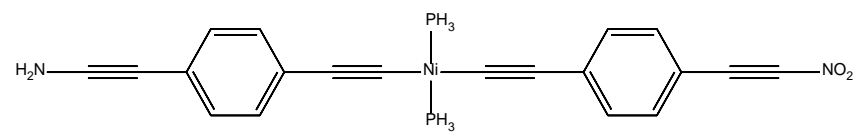

26.2

128

$-102$

$-1.3$

75

0.74

- the unit of $\beta: 4.2 \times 10^{-40} \mathrm{~m}^{4} / \mathrm{V}, M$ : the percentage of a major excitation contributed. $C_{C I}$ : the mixing coefficient of interaction.

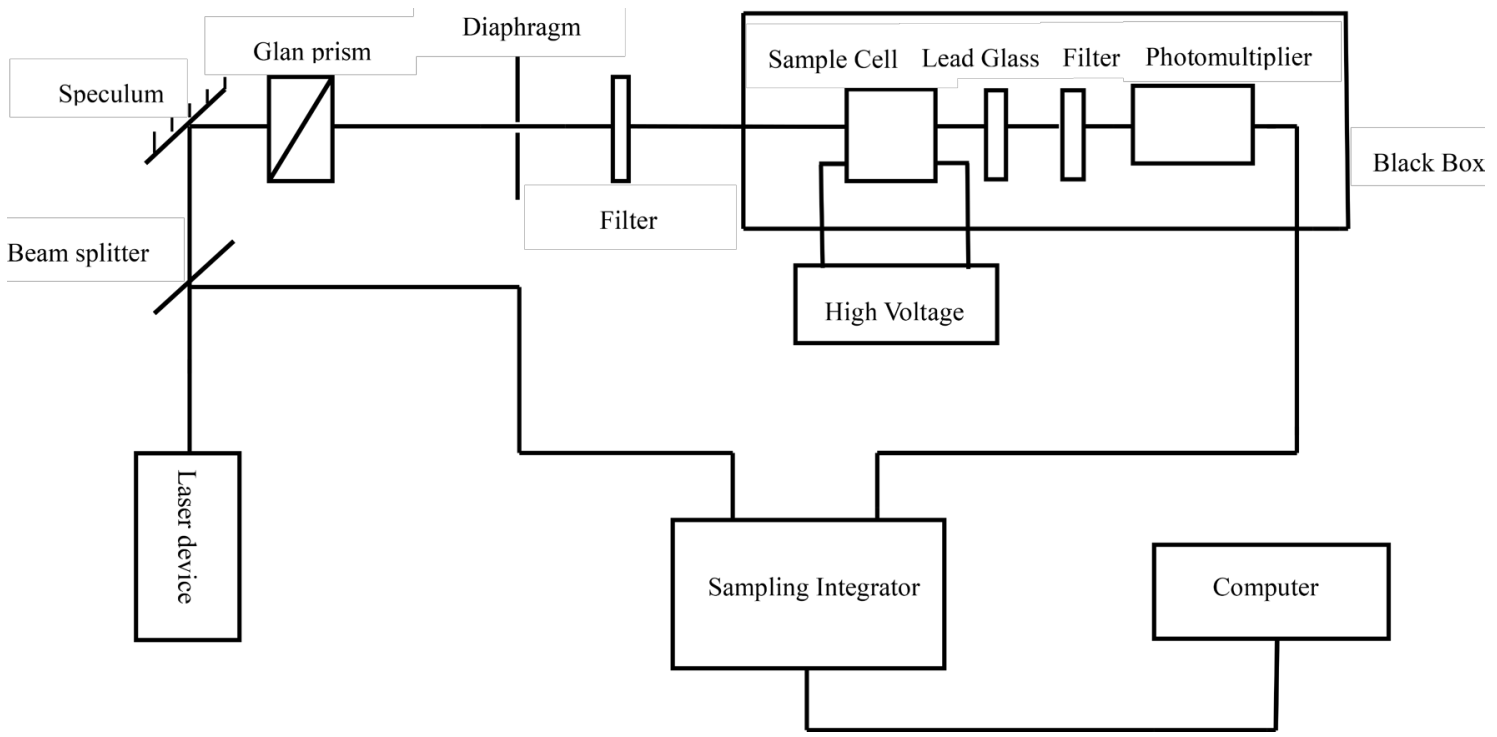

Figure 1. Experimental setup for the EFISH technique.

Using heat-insulating lead glass and interference filter to filter out the fundamental frequency light passing through the sample cell, and the frequency-doubled signal is received by a low-noise, high-sensitivity photomultiplier tube. When measuring quartz samples, a central attenuator must be added to prevent the signal from being too strong to reduce the sensitivity of the photomultiplier tube. The signal is averaged by the sampling integrator and recorded 
by the computer. In order to ensure the reliability of the relative ratio of light intensity, the quartz sample is retested at fixed intervals (about half an hour). It summarizes the whole process of EFISH experimental data processing (Figure 2 ), which is mainly used to determine the nonlinear polarizability in the direction of the molecular dipole moment. The basic idea is that the molecules are randomly arranged in a disorderly manner in a liquid or solution state. Even if the molecules themselves have a non-centrosymmetric structure, their even sub-polarization affects cancel each other out, and the average value of the system is still zero. If a high voltage electrostatic field is added to the system, the inherent dipole moment of the molecules will cause the molecules to be aligned under the action of an applied electric field, thus generating the macroscopic frequency doubling effect that can be measured. According to the magnitude of the frequency doubling signal, the second-order nonlinear polarimetry of a single molecule is calculated. This method has become the most accurate and effective method to measure the second order nonlinear polarizability of molecules. The experimental technique can be used to study the second order nonlinear response by means of equations:

$$
\gamma_{E F I S H}=\left(\mu \beta_{\lambda} / 5 \kappa T\right)+\gamma(-2 \omega ; \omega, \omega, 0)
$$

$\mu \beta_{\lambda} / 5 \kappa T$ : dipolar orientational contribution $\gamma(-2 \omega ; \omega, \omega, 0)$ : the electronic contribution to EFISH which is negligible for dipolar molecules is the projection along the dipole moment axis of the vectorial component of the tensor of the quadratic hyperpolarizability, working with an incident wavelength. $\mu$ is the ground state dipole moment. Extrapolation to zero frequency $\left(\vee_{\Lambda}=0.0 \mathrm{eV} ; \lambda=\infty\right)$ obtains the determination of $\mu \beta_{0}$ where $\beta_{0}$ is the static quadratic hyperpolarizability, it is a key point for comparing the second-order NLO properties of molecules. The $\mu \beta_{0}$ value can be obtained by the following equation:

$$
\mu \beta_{0}=\mu \beta_{\lambda}\left[1-\left(2 \lambda_{\max } / \lambda\right)^{2}\right]\left[1-\left(\lambda_{\max } / \lambda\right)^{2}\right]
$$

$\lambda$ and $\lambda_{\max }$ is the absorption wavelength. A molecule having a $\mu \beta_{0}$ higher than that of Disperse Red One $\left(450 \times 10^{-48} \mathrm{esu}\right)$, which can prepare stable NLO-active hybrid polymeric films [24]. When determining the quadratic hyperpolarizability, it is necessary to ensure that an incident wavelength is far from the absorption wavelengths of the investigated compound.

1) quadratic hyperpolarizability of donor-acceptor molecules

The main feature of push-pull molecules is that they are conjugated by the

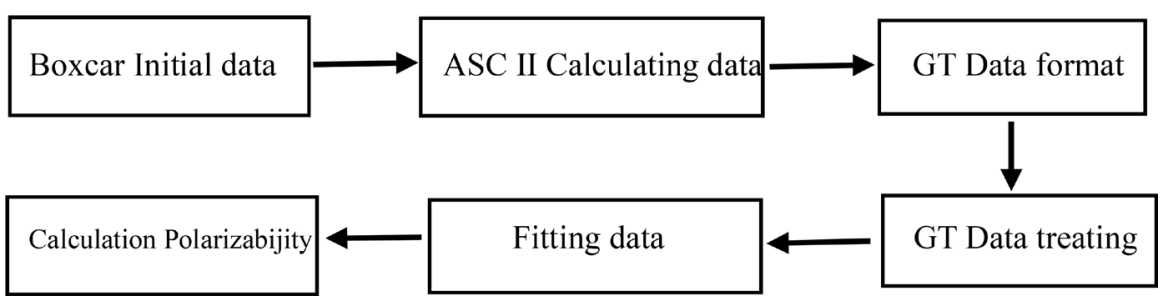

Figure 2. Data processing of the EFISH experiment. 
principal end group, which makes the molecules have attractive optical nonlinearity. The strong absorption of these molecules in the ultraviolet region and the large ground state molecular dipole moment are mainly due to the influence of intramolecular charge transfer (ICT). The significant dipole moment variation is caused by the transition from the ground state to the excited state, and the static secondary polarizability is obtained between the ground state and the excited state. Secondary hyperpolarizability plays an important role in intramolecular charge transfer [25]. In brief, as shown in Figure 3, push-pull polyolefin can be seen as a mixture of the two forms of ultimate resonance. For most polyolefins, There is little correlation between hyperpolarizability and geometric parameters. Nonetheless, for push-pull polyolefin, Maker and coworkers reported that in the molecular structure the band length alternation (BLA) and $\pi$-electron bond order alternation make a huge positive effect on the hyperpolarizability [26]. In the analysis we used, the ground state and the first excited state (ICT) were described as a linear combination of the neutral (N) and amphoteric (Z) wave functions corresponding to the two resonant forms. In a quadratic approximation, the function of $\mathrm{V}$ and $\mathrm{T}$ can be represented as a dependent parameter. $\mathrm{V}$ is the band between $\mathrm{Z}$ and $\mathrm{N}$. $\mathrm{T}$ the non diagonal coupling element. Herein, we can define a MIX parameter that determines the resonance shape. This paraeter is only a function of $\mathrm{V}$ and $\mathrm{T}$. We analyze the relationship between secondary hyperpolarimetry and MIX. The necessary condition for producing the maximum secondary hyperpolarizability is the existence of an optimal mixture between the finite resonance forms ( $\mathrm{MIX}= \pm 0.45)$ [27].

As shown in Figure 4, it is the most representative push-pull polyolefin studied so far. The experimental values $\mu \beta(0)$ measured by EFISH technology are listed in Table 2. We calculated the mixed values as well as the $\beta_{\mathrm{CT}}(0)$ and $\beta_{\max }$ (0) values using data from both absorption and electro-optical absorption measurements (EOAM) via a two-state bimorphological model [28]. The experimental value (0) and the calculated value CT (0) increased as the molecules grew,

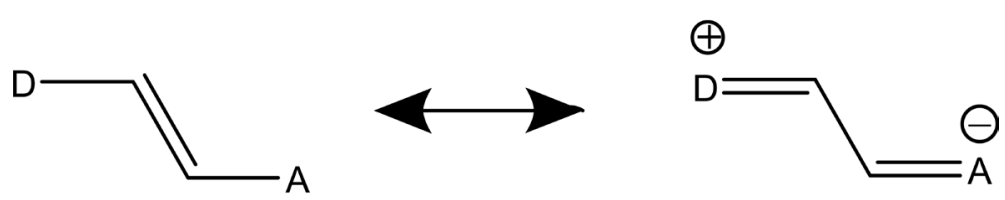

Figure 3. Neutral and zwitterionic resonance forms of push-pull polyenes.

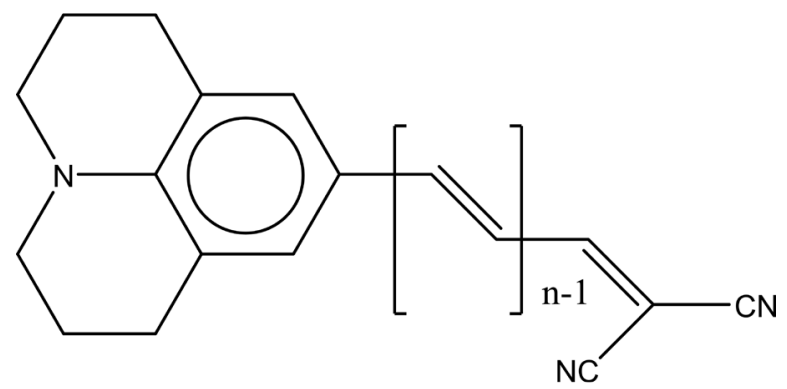

Figure 4. Structural formula of the series of molecules investigated. 
Table 2. The $\beta$ hyperpoiarizabilities are given in $10^{-30} \mathrm{esu}$ [28].

\begin{tabular}{ccccc}
\hline $\mathrm{n}$ & $\mathrm{MIX}$ & $\boldsymbol{\beta}_{\mu}(\mathbf{0})$ & $\boldsymbol{\beta}_{\mathrm{CT}}(\mathbf{0})$ & $\beta_{\mathrm{CT}}(\mathbf{0})$ \\
\hline 1 & -0.49 & 32 & 35 & 36 \\
2 & -0.65 & 97 & 96 & 129 \\
3 & -0.73 & 210 & 200 & 368 \\
4 & -0.76 & 405 & 288 & 600 \\
\hline
\end{tabular}

The accuracy of the experimental values $\beta_{\mu}(0)$ is about $10 \%$. The MIX and $\beta_{\max }(0)$ computed values obtained with the two-state two-form model. $\beta_{\mathrm{CT}}(0)$ from ref. [29].

but remained essentially the same except for long chains of $n=4$, indicating that the quadratic approximation was suitable for push-pull polyolefins (Table 2). At the same time for short-chain compounds, the mixing value is almost optimized. But as the chain grows, the MIX value deviates more and more from the optimized value. Whereas, $\beta_{\max }(0)$ increased significantly, resulting in a significant increase in the second-order nonlinearity. This indicates that the growth of chain has a direct effect on the secondary hyperpolarimetry of these compounds.

\section{2) Cyclometalated Ir (III) Complexes with Curcuminoid Ligands}

It is well known that for pyridine-based iridium metal organic complexes, the free 2-phenylpyridine NLO response is very weak. Therefore, the metal iridium and the cyclometalization reaction play a decisive role in improving the nonlinear activity of such metal complexes. After studying a family of iridium (III) acetylacetonate compounds with various cyclometalated 4-styryl-2-phenylpyridines substituents $\left(\mathrm{NEt}_{2}, \mathrm{OMe}, \mathrm{NO}_{2}\right)$, In order to undestand that whether appropriate functionalization of 2-phenylpyridine ligands is beneficial to the improvement of secondary NLO activity [30]. The results indicate that the $\mu \beta_{1.907}$ value of the 4-styryl-2-phenylpyridine bearing the nitro group, is comparable to 2-phenylpyridine [34]. Undoubtedly, Iridium phosphorescent (III) complexes, two epoxided 2-phenylpyridine ligands and acetylacetone as auxiliary ligands have become the leading ones in the field of NLO research. But, this kind of hybrid polymer film was declared a failure by reason of its unstable nonlinear activity. As shown in Figure 5, As a consequence that researching two iridium (III) complexes with two cyclometalated 2-phenylpyridines and curcumin (complex 1) or tetrahydrocurcumin (complex 2) as an ancillary ligand. The complexes 1 and 2 were determined in chloroform solution $\left(10^{-3} \mathrm{M}\right)$ by The Electric Field Induced Second Harmonic generation (EFISH) method. For complexes $\operatorname{Ir}_{1}$ and $\operatorname{Ir}_{2}$, we choose a $1.907 \mu \mathrm{m}$ as incident wavelength achieved by Raman-shifting the $1.064 \mu \mathrm{m}$ wavelength obtained from a Q-switched, mode-locked Nd: YAG laser.

Obviously, the values of these two iridium metal complexes are negative. The $\mu \beta_{1.907}$ value of complex $\operatorname{Ir}_{1}$ is $-1050 \times 10^{-48}$ esu, $-930 \times 10^{-48}$ esu for complex $\operatorname{Ir}_{2}$ respectively. Some studies show that the $\mu \beta_{1.907}$ value of other cyclometalated iridium (III) complexes with $\beta$-diketonate is also negative [31] [32]. Hence it indicates that value of $\Delta \mu_{n g}$ (difference of the dipole moment in the excited state and in the ground state) is negative following the "two-level" model [33] [34]. 
<smiles>COc1cc(/C=C/C2=CC(/C=C/c3ccc(O)c(OC)c3)=NP(=O)(c3ccccc3)O2)ccc1O</smiles><smiles></smiles>

Figure 5. Investigated Iridium (III) complexes.

For complex $\operatorname{Ir}_{1}$, the $\mu \beta_{1.907}$ experimental value $\left(-1050 \times 10^{-48} \mathrm{esu}\right)$ is comparable to $\mu \beta_{0}$ calculated value $\left(-747 \times 10^{-48} \mathrm{esu}\right)$ by Equation (7). The low energy charge transfer absorption band (470 $\mathrm{nm}[35]$ ) much higher than that of Disperse Red One [24] and slightly larger than that of the related complex with acetylacetonate instead of the curcumin ligand. The complex $\operatorname{Ir}_{2}$ with tetrahydrocurcumin as an ancillary ligand has a similar second-order NLO response $\left(\mu \beta_{1.907}=-930 \times\right.$ $10^{-48}$ esu; $\mu \beta_{0}=-661 \times 10^{-48}$ esu by Equation (7) and $\lambda_{\max }=470 \mathrm{~nm}$ [36]. It is a tempting conclusion that because of their unique characteristics of luminescence and nonlinear optical properties, these compounds have become the focus of multifunctional molecular photoelectronic materials, attracting the attention of scientists and researchers today [37]-[46]. In Ir (III) complexes, the second-order NLO response mainly caused by various charge transfer transitions. And the observed negative value of $\beta_{1.907}$ EFISH is the result of positive and negative contributions to the quadratic hyperpolarizability [4] [32].

\section{3) Iridium complexes with anellated hemicyanine ligands}

The second-order NLO activity of anellated hemicyanine ligands [N,N-dimetyl-4-(pyridin-4-yl)aniline, $\mathrm{L}_{1}$ and $\mathrm{N}$-methyl-N-hexadecylaminostilbazole, $\mathrm{L}_{2}, 7-\mathrm{N}, \mathrm{N}$-dibutylamino-2-azaphenanthrene, $\mathrm{L}_{3}$, and 8-N,N-dibutylamino-2azachrysene, $\mathrm{L}_{4}$. systems containing an electron-withdrawing substituent $(-\mathrm{CN})$, 
$\mathrm{L}_{5}$ ], and iridium(III) compounds with anellated hemicyanine ligands $\left\{\right.$ cis- $\left[\operatorname{Ir}(\mathrm{CO})_{2} \mathrm{ClL}_{3}\right], \operatorname{IrL}^{3}$, and cis- $\left.\left[\operatorname{Ir}(\mathrm{CO})_{2} \mathrm{ClL}_{4}\right], \operatorname{IrL}^{4}\right\}$ have been investigated (Figure 6) [47]. Their second-order NLO activity was studied by EFISH techniques and the values $\mu \beta_{1.907}$ (EFISH) of iridium(III) compounds with anellated hemicyanine ligands are reported in Table 2, Table 3. With study of these iridium (III) compounds, we obtained that the selected compound $\mathrm{L}^{1}$ in trichloromethane solution present a low absolute value of $\mu \beta_{1.907}$ (EFISH) $\left(48 \times 10^{-48} \mathrm{esu}\right)$, which can be attributed to the absence of a complete $\pi$-conjugation between the two aromatic rings. However the absolute value of $\mu \beta_{1.907}$ (EFISH) (L $\mathrm{L}^{3}: 430 \times$ $10^{-48} \mathrm{esu}$ ) is 8.9 times as much as $\mathrm{L}^{1}$, which is due to include the single bond into the polyaromatic scaffold of $\mathrm{L}^{3}$. It is quite clear that a continuous enhancement of the $\pi$-conjugation for the free ligand gives rise to a huge positive effect on the second order NLO response. Hence, the absolute value of $\mu \beta_{1.907}$ (EFISH) of the free ligands: $\mathrm{L}^{3}$ and $\mathrm{L}^{4}$ is much lagerer $\left(430 \times 10^{-48} \mathrm{esu}, 1800 \times 10^{-48} \mathrm{esu}\right)$ than that of $\mathrm{L}^{2}\left(223 \times 10^{-48} \mathrm{esu}\right)$. Strangely enough, there is different to what was observed in the case of stilbazolium salts [48] [49], the effect of methylation of the pyridine ring of $\mathrm{L}^{4}$ to the second order NLO is weak, although generating a bathochromic shift of the ILCT transition. That is usually originated from the difference in the direction of the dipole moment, which governs the overall EFISH response. More surprisingly, the $\beta$ values of $\mathrm{L}^{3}$ and $\mathrm{L}^{4}$ ligands are large and positive, which become decrease and even negative. When coordinated (Table 3).

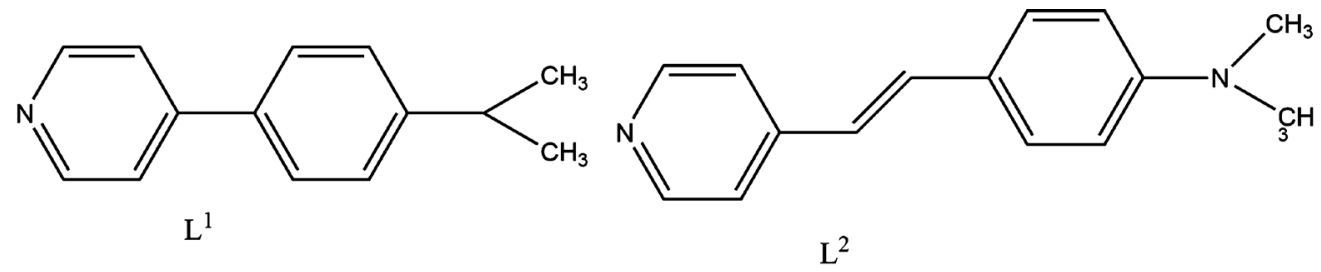

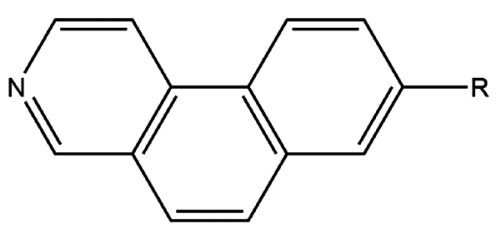

$\mathrm{L}^{3} \mathrm{R}=\mathrm{NBu}_{2}$

$\mathrm{L}^{5} \mathrm{R}=\mathrm{CN}$

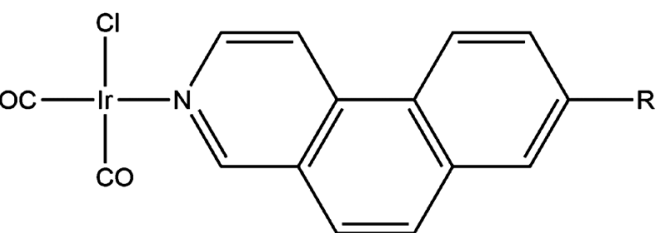

$\left[\mathrm{IrL}^{3}\right] \mathrm{R}=\mathrm{NBu}_{2}$

$\left[\mathrm{IrL}^{5}\right] \mathrm{R}=\mathrm{CN}$

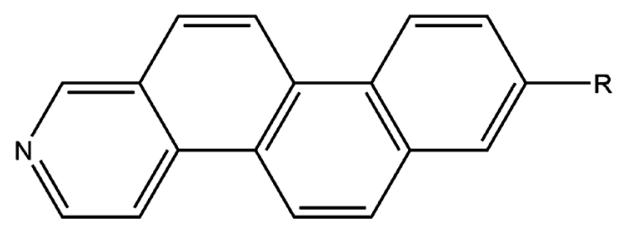

$\mathrm{L}^{4} \mathrm{R}=\mathrm{NBu}_{2}$

$\mathrm{L}^{6} \mathrm{R}=\mathrm{CN}$

Figure 6. Schematic structure of anellated hemicyanine ligand and their related iridium complexes. 
Table 3. EFISH $\mu \beta_{1907}$ and $\mu$ values of ligands $\mathrm{L}_{3}$ and $\mathrm{L}_{4}$ and related iridium complexes [50].

\begin{tabular}{cccc}
\hline & $\mu \beta_{1.907^{\mathrm{a}, \mathrm{b}}}\left(\times 10^{-48}\right.$ esu $)$ & $\mu^{\mathrm{c}}\left(\mu_{\text {theor }}\right)[\mathrm{D}]$ & $\beta_{1.907}\left(\times 10^{-30}\right.$ esu $)$ \\
\hline $\mathrm{L}^{1}$ & 48 & 2.4 & $20^{\mathrm{d}}$ \\
$\mathrm{L}^{2}$ & $223^{\mathrm{e}}$ & $3.7^{\mathrm{e}}$ & $60^{\mathrm{e}}$ \\
$\mathrm{L}^{3}$ & 430 & $3.5(7.6)$ & $123^{\mathrm{d}}(56)^{\mathrm{e}}$ \\
{$\left[\operatorname{IrL}^{3}\right]$} & 620 & $(16.2)$ & $(38)^{\mathrm{e}}$ \\
$\mathrm{L}^{4}$ & 1800 & $4.2(8.0)$ & $429^{\mathrm{d}}(224)^{\mathrm{e}}$ \\
{$\left[\operatorname{IrL}^{4}\right]$} & -2310 & $(16.9)$ & $(-137)^{\mathrm{e}}$ \\
\hline
\end{tabular}

${ }^{\mathrm{a}} \mathrm{EFISH}$ values determined in $\mathrm{CHCl}_{3}$ with an incident wavelength of $1.907 \mathrm{~mm} .{ }^{\mathrm{b}} \mathrm{The}$ error on EFISH measurements is $\pm 10 \%$. 'Values measured in $\mathrm{CHCl}_{3}$ by the Guggenheim method. ${ }^{\mathrm{d}} \mathrm{By}$ using experimental $\mu$. ${ }^{\mathrm{e}}$ Data from ref.[47].

Table 4. NLO response of $\mathrm{CN}$ substituted ligands, $\mathrm{L}^{5}$ and $\mathrm{L}^{6}$ and related iridium complexes [50].

\begin{tabular}{cccc}
\hline Ligands & $\mu \beta_{1.907}\left(\times 10^{-48} \text { esu }\right)^{\mathrm{a}}$ & Complexes & $\mu \beta_{1.907}\left(\times 10^{-48} \mathrm{esu}\right)^{\mathbf{a}}$ \\
\hline $\mathrm{L}^{3}$ & 587 & {$\left[\mathrm{IrL}^{3}\right]$} & 819 \\
$\mathrm{~L}^{5}$ & -1030 & {$\left[\operatorname{IrL}^{5}\right]$} & -2350 \\
$\mathrm{~L}^{6}$ & -1830 & {$\left[\operatorname{IrL}^{6}\right]$} & -1990 \\
\hline
\end{tabular}

${ }^{\mathrm{a}} \mathrm{In} \mathrm{DMF}$ at $10^{-4} \mathrm{M}$ with an incident radiation of $1.907 \mu \mathrm{m}$. The error on EFISH measurements is $\pm 10 \%$.

With this fundamental concern, it is easy to find that the $\mu$ of the ground state is lower than that of the excited state. This can be explained by two factors: ILCT transition $(\beta>0)$ and MLCT transition $(\beta<0)$. As shown in Table 3 , This behaviour is compared to the observed upon coordination of $\mathrm{L}^{2}$ to the same $\operatorname{Ir}(\mathrm{I})$ moiety where $\mu \beta_{1.907}$ is enhanced but remains positive, being dominated by an ILCT Transition [47]. The increasing NLO response when an annine substituted with a withdrawing group, $\mathrm{CN} \mathrm{L}^{5}$, is coordinated to the iridium fragment would be in agreement with the importance of the MLCT transition (Table 4).

4) Cationic cyclometallated iridium (III) complexes with substituted 1,10-phenanthrolines

A family of $\operatorname{Ir}(\mathrm{III})$ complexes of [Ir(ppy)2(5-R-1,10-phen)] [PF6] (ppy = cyclometallated 2-phenylpyridine), (1a-b), $\left[\operatorname{Ir}(\operatorname{ttpy})_{2}(5-\mathrm{R}-1,10-\mathrm{phen})\right]\left[\mathrm{PF}_{6}\right](\mathrm{ttpy}=$ cyclometallated 3'-(2-pyridil)-2,2':5',2"-terthiophene, phen = phenanthroline; $\left.2 \mathrm{a}-\mathrm{b}, \mathrm{R}=\mathrm{Me}, \mathrm{NO}_{2}\right)$ and $\left[\operatorname{Ir}(\mathrm{pq})_{2}(5-\mathrm{R}-1,10-\mathrm{phen})\right]\left[\mathrm{PF}_{6}\right](\mathrm{pq}=$ cyclometallated 2 -phenylquinoline, 3a-b) was investigated (Figure 7). The $\mu \beta$ values of these six complexes were determined by the EFISH method working in $\mathrm{CH}_{2} \mathrm{Cl}_{2}$. All compounds show a negative $\mu \beta_{1.907}$ (EFISH) (Table 5), ranging from $-1320 \times 10^{-48}$ esu to $-2230 \times 10^{-48}$ esu. Complex [Ir(ppy)2(5-R-1,10-phen)] [PF6] (ppy= cyclometallated 2-phenylpyridine) shows a large absolute value of $\mu \beta_{1.907}$ (EFISH), which presents a strong second order NLO response [51] and luminescence properties [52], A slightly higher value is observed for $\left[\operatorname{Ir}(\mathrm{pq})_{2}(5-\mathrm{R}-1,10-\mathrm{phen})\right]$ $\left[\mathrm{PF}_{6}\right]$ ( $\mathrm{pq}=$ cyclometallated 2-phenylquinoline). Substitution of ppy with the 
<smiles></smiles>

$\mathrm{R}=\mathrm{Me} \quad \mathrm{la}$ $\mathrm{R}=\mathrm{NO}_{2} \mathrm{lb}$

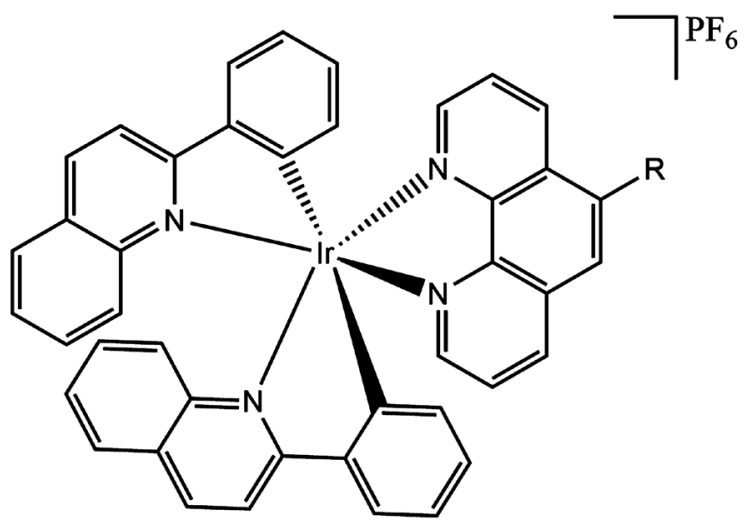

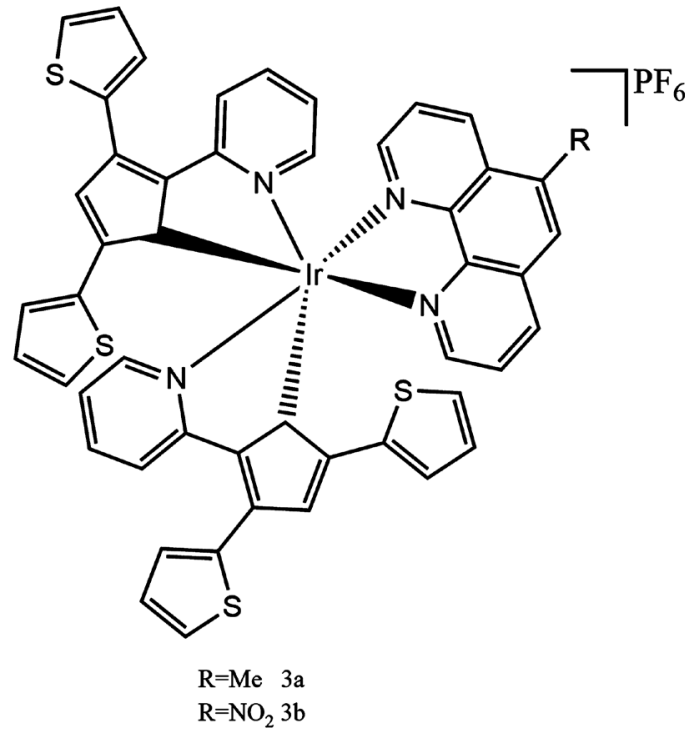

$\mathrm{R}=\mathrm{Me} \quad 2 \mathrm{a}$ $\mathrm{R}=\mathrm{NO}_{2} 2 \mathrm{~b}$

Figure 7. Bis-cyclometalated phenylpyridine iridium (III) complexes with phenanthroline ligands.

Table 5. Absorption and emission maxima, $\Phi$ and EFISH $\mu \beta_{1907}$ values in $\mathrm{CH}_{2} \mathrm{Cl}_{2}$ of 1 - 3 complexes [53].

\begin{tabular}{|c|c|c|c|c|}
\hline & Absorption $\max (\mathrm{nm})$ & $\begin{array}{l}\text { Emission max } \\
(\mathrm{nm})\end{array}$ & Quantum yield $\Phi(\%)$ & $\begin{array}{c}\text { EFISH } \mu \beta_{1907^{\mathrm{a}, \mathrm{b}}} \\
\left(10^{-30} \mathrm{Dcm}^{5} \mathrm{esu}^{-1}\right)\end{array}$ \\
\hline 1a & $255(\mathrm{sh}), 268,333(\mathrm{sh}), 377^{\mathrm{cdd}}$ & $559^{c}$ & $38^{\mathrm{c}}$ & $-1565^{e}$ \\
\hline $1 b$ & $254(\mathrm{sh}), 264,378^{\mathrm{c}, \mathrm{d}}$ & - & $<0.1^{\mathrm{c}}$ & $-2230^{e}$ \\
\hline $2 \mathrm{a}$ & $273,329,347(\mathrm{sh}), 431^{\mathrm{cdd}}$ & $556^{\mathrm{c}}$ & 34 & -2090 \\
\hline $2 b$ & $268,324,430^{c, d}$ & - & $<0.1^{\mathrm{c}}$ & -1720 \\
\hline $3 a$ & $260,319(\mathrm{sh}), 396^{\mathrm{d}}$ & 563 & 1.3 & -1320 \\
\hline $3 b$ & $250(\mathrm{sh}), 264,360(\mathrm{sh}), 377,407(\mathrm{sh})^{\mathrm{d}}$ & - & $<0.1$ & -1640 \\
\hline
\end{tabular}

${ }^{a} \mathrm{EFISH}$ measurements are carried out in $\mathrm{CH}_{2} \mathrm{Cl}_{2}$ at $10^{-3} \mathrm{M}$; ${ }^{\mathrm{b}} \mathrm{The}$ error of EFISH measurements is $\pm 10 \%$; ${ }^{\mathrm{R}} \mathrm{Ref}$. [51]; ${ }^{\mathrm{d}} \mathrm{There}$ is a band tail above $400 \mathrm{~nm}$ up to about $500-550 \mathrm{~nm}$; ${ }^{~}$ Ref. [51]. 
more $\pi$-delocalized pq does not affect significantly the luminescence and NLO properties. A slightly lower NLO response and a much poorer luminescence is observed for the related complexes with ttpy. It is worthwhile mentioning that these complexes have unique characteristics in good transparency towards the second harmonic emission renders appealing as building blocks for composite second order NLO materials [51]. The quadratic hyperpolarizability $\beta$ of $2 \mathrm{a}-\mathrm{b}$ and 3a-b was measured by the EFISH technique [53] at $1907 \mathrm{~nm}$ incident wavelength in $\mathrm{CH}_{2} \mathrm{Cl}_{2}$. Comparison of the properties of 2a-b with that of $1 \mathrm{a}-\mathrm{b}$ puts in evidence that substitution of ppy with the more $\pi$-delocalized pq does not affect significantly the luminescence and NLO properties(Table 5).

\section{Concluding Remarks}

In this review, the nonlinear optical properties of iridium complexes were investigated, the relationship between their NLO activity and molecular structure was elucidated, and the great potential of iridium complexes in NLO optical materials was demonstrated. Nonlinear polarimetry is one of the main indexes to measure the quality of nonlinear optical materials, and its size is directly related to the molecular structure. Therefore, studying the molecular nonlinear polarimetry at the molecular level is of great help to design new and efficient nonlinear optical devices. There are several methods to determine the second-order nonlinear polarizability of molecules. At present, the most accurate and effective method is EFISH experimental method, namely EFISH(electric-field-induced second harmonic wave) method, which is used to determine the nonlinear polarizability in the direction of the molecular dipole moment. Which provides a bridge between micromolecules and molecular engineering, and points the way for synthetic chemists and materials scientists to find new nonlinear optical materials. In this paper, the working principle, experimental steps and calculation results of EFISH method are introduced in detail, and the results are discussed preliminarily. In this paper, the working principle, experimental steps and calculation of EFISH method are introduced in detail, and the results are discussed preliminarily. For most polyolefins, there is little correlation between hyperpolarization and geometric parameters. Nonetheless, for push-pull polyolefin, Maker and coworkers have been proved that in the molecular structure the band length alternation (BLA) and $\pi$-electron bond order alternation make a hugely positive effect on the hyperpolarizability [26]. For pyridine iridium metal organic complexes, free 2-phenylpyridine NLO response is very weak. Herein, the metal iridium and the cyclometalization reaction play a decisive role in improving the nonlinear activity of such metal complexes. It is no doubt that iridium (III) complex with tetrahydrocurcumin ligands are distinguished from NLO research. Additionally, due to the large nonlinear optical coefficient of organic molecular nonlinear optical materials, wide response band, good flexibility, high light damage threshold and low cost, as well as easy synthesis and can be cut and modified, the organic molecular nonlinear optical materials have attracted much 
attention. Looking forward, the experimental work will be devoted to achieving the efficient conversion into light or redox of the second order NLO activity. The iridium complex has the properties of second order NLO and has the potential to combine second order NLO, two-photon absorption and luminescence and other functional materials.

\section{Acknowledgements}

Financial support from the National Natural Science Foundation of China (Grants 50925207, 51172100, 51432006, and 51602130), the Ministry of Science and Technology of China for the International Science Linkages Program (Grants 2009DFA50620 and 2011DFG52970), the Ministry of Education of China for the Changjiang Innovation Research Team (Grant IRT13R24), the Ministry of Education and the State Administration of Foreign Experts Affairs for the 111 Project (Grant B13025), 100 Talents Program of CAS, Jiangsu Innovation Research Team and Natural Science Foundation of the Higher Education Institutions of Jiangsu Province (Grant 16KJD430002) are gratefully acknowledged.

\section{Conflicts of Interest}

The authors declare no conflicts of interest regarding the publication of this paper.

\section{References}

[1] Nalwa, H.S. (1993) Organic Materials for Third-Order Nonlinear Optics. Advanced Materials, 5, 341-358. https://doi.org/10.1002/adma.19930050504

[2] Hu, Y.X., et al. (2019) Recent Developments in Benzothiazole-Based Iridium(III) Complexes for Application in Oleds as Electrophosphorescent Emitters. Organic Electronics, 66, 126-135. https://doi.org/10.1016/j.orgel.2018.12.029

[3] Di Bella, S., Colombo, A., Dragonetti, C., Righetto, S. and Roberto, D. (2018) Zinc(II) as a Versatile Template for the Preparation of Fascinating Dipolar and Octupolar Second-Order Nonlinear Optical Molecular Materials. Inorganics, 6, 133. https://doi.org/10.3390/inorganics6040133

[4] Colombo, A., Dragonetti, C., Guerchais, V., Hierlinger, C. and Roberto, D. (2020) A Trip in the Nonlinear Optical Properties of Iridium Complexes. Coordination Chemistry Reviews, 414, Article ID: 213293.

https://doi.org/10.1016/j.ccr.2020.213293

[5] Yu, G., Zhao, X., Niu, M., et al. (2013) Constructing a Mixed $\pi$-Conjugated Bridge: A Simple and Effective Approach to Realize a Large First Hyperpolarizability in Carbon Nanotube-Based Systems. Journal of Materials Chemistry C, 1, 3833-3841. https://doi.org/10.1039/c3tc00022b

[6] Kurtz, H.A., Stewart, J.J., Dieter, K.M., et al. (1990) Calculation of the Nonlinear Optical Properties of Molecules. Journal of Computational Chemistry, 11, 82-87. https://doi.org/10.1002/jcc.540110110

[7] Adair, R., Chase, L.L., Payne, S.A., et al. (1989) Nonlinear Refractive Index of Optical Crystals. Physical Review B, 39, 3337-3350. https://doi.org/10.1103/PhysRevB.39.3337

[8] Man, W., Fardad, S., Zhang, Z., et al. (2013) Optical Nonlinearities and Enhanced 
Light Transmission in Soft-Matter Systems with Tunable Polarizabilities. Physical Review Letters, 111, Article ID: 218302. https://doi.org/10.1103/PhysRevLett.111.218302

[9] Base, K., Tierney, M.T., Fort, A., et al. (2013) On the Second-Order Nonlinear Optical Structure-Property Relationships of Metal Chromophores. Inorganic Chemistry, 38, 287-289. https://doi.org/10.1021/ic980872q

[10] Marowsky, G., Chi, L., Mobius, D., et al. (1988) Non-Linear Optical Properties of Hemicyanine Monolayers and the Protonation Effect. Chemical Physics Letters, 147, 420-424. https://doi.org/10.1016/0009-2614(88)85002-4

[11] Bussmannholder, A. (2012) The Polarizability Model for Ferroelectricity in Perovskite Oxides. Journal of Physics: Condensed Matter, 24, Article ID: 273202. https://doi.org/10.1088/0953-8984/24/27/273202

[12] Gorman, C.B. and Marder, S.R. (1995) Effect of Molecular Polarization on Bond-Length Alternation, Linear Polarizability, First and Second Hyperpolarizability in Donor-Acceptor Polyenes as a Function of Chain Length. Chemistry of Materials, 7, 215-220. https://doi.org/10.1021/cm00049a033

[13] Maury, O. and Le Bozec, H. (2010) Molecular Materials. In: Bruce, D.W., O'Hare, D. and Walton, R.I., Eds., Metal-Based Quadratic Molecular Materials, Wiley, Chichester, Chap. 1. https://doi.org/10.1002/9780470686058.ch1

[14] Kaur, N., Van Steerteghem, N., Singla, P., et al. (2017) Second-Order Nonlinear Polarizability of Ferrocene-BODIPY Donor-Acceptor Adducts. Quantifying Charge Redistribution in the Excited State. Dalton Transactions, 46, 1124-1133. https://doi.org/10.1039/C6DT04455G

[15] Green, M.L.H., Marder, S.R., Thompson, M.E., Bandy, J.A., Bloor, D., Kolinsky, P.V. and Jones, R.J. (1987) Synthesis and Structure of (Cis)-[1-ferrocenyl2-(4-nitrophenyl)ethylene], an Organotransition Metal Compound with a Large Second-Orderoptical Nonlinearity. Nature, 330, 360-362. https://doi.org/10.1038/330360a0

[16] Liu, C. and Guan, X. (2013) Computational Study on Redox-Switchable Second-Order Nonlinear Optical Properties of Totally Inorganic Keggin-Type Polyoxometalate Complexes. Journal of Physical Chemistry C, 117, 7776-7783. https://doi.org/10.1021/jp400185a

[17] Ledoux, I. and Zyss, J. (1982) Influence of the Molecular Environment in Solution Measurements of the Second-Order Optical Susceptibility for Urea and Derivatives. Chemical Physics, 73, 203-213. https://doi.org/10.1016/0301-0104(82)85161-6

[18] Coe, B.J. (2004) Comprehensive Coordination Chemistry II. In: McCleverty, J.A. and Meyer, T.J., Eds., Nonlinear Optical Properties of Metal Complexes, Volume 9, Elsevier Pergamon, Oxford, 621-687. https://doi.org/10.1016/B0-08-043748-6/09018-6

[19] Valore, A., Balordi, M., Colombo, A., Dragonetti, C., Righetto, S., Roberto, D., Ugo, R., Benincori, T., Rampinini, G., Sannicolò, F. and Demartin, F. (2010) Novel Ruthenium(II) Complexes with Substituted 1,10-Phenanthroline or 4,5-Diazafluorene Linked to a Fullerene as Highly Active Second Order NLO Chromophores. Dalton Transactions, 39, 10314-10318. https://doi.org/10.1039/c0dt00686f

[20] Prasad, P.N. and Williams, D.J. (1991) Introduction to Nonlinear Optical Effects in Molecules and Polymers. John Wiley \& Sons Inc., Hoboken, 106-130.

[21] Levine, B.F. and Bethea, C.G. (1974) Molecular Hyperpolarizabilities Determined from Conjugated and Nonconjugated Organic Liquids. Applied Physics Letters, 24, 445-447. https://doi.org/10.1063/1.1655254 
[22] Levine, B.F. and Bethea, C.G. (1975) Second and Third Order Hyperpolarizabilities of Organic Molecules. The Journal of Chemical Physics, 63, 2666-2682. https://doi.org/10.1063/1.431660

[23] Qian, S.X. and Wang, G.M. (2001) Principles and Progress of Nonlinear Optics. Xiamen University Press, Xiamen, 50.

[24] Singer, K.D., Sohn, J.E., King, L.A., et al. (1989) Second-Order Nonlinear-Optical Properties of Donor- and Acceptor-Substituted Aromatic Compounds. Journal of the Optical Society of America B: Optical Physics, 6, 1339-1350. https://doi.org/10.1364/JOSAB.6.001339

[25] De Angelis, F., Fantacci, S., Evans, N., Klein, C., Zakeeruddin, S.M., Moser, J.E. Kalyanasundaram, K., Bolink, H.J., Graetzel, M. and Nazeeruddin, M.K. (2007) Controlling Phosphorescence Color and Quantum Yields in Cationic Iridium Complexes: A Combined Experimental and Theoretical Study. Inorganic Chemistry, 46, 5989-6001. https://doi.org/10.1021/ic700435c

[26] Barzoukas, M., Runser, C., Fort, A. and Blanchard-Desce, M. (1996) A Two-State Description of (Hyper) Polarizabilities of Push-Pull Molecules Based on a Two-Form Model. Chemical Physics Letters, 257, 531-537. https://doi.org/10.1016/0009-2614(96)00586-6

[27] Fort, A., Barzoukas, M., Muller, J., et al. (1997) Enhanced Quadratic Hyperpolarizability of Donor-Acceptor Molecules Experimental and Analytical Investigations. Journal of Luminescence, 72-74, 494-495. https://doi.org/10.1016/S0022-2313(96)00225-6

[28] Blanchard-Desce, M., Alain, V., Midrier, L., Wortmann, R. and Barzoukas, M. (1997) Intramolecular Charge Transfer and Enhanced Quadratic Optical Non- Linearities in Push Pull Polyenes. Journal of Photochemistry \& Photobiology A Chemistry, 105, 115-121. https://doi.org/10.1016/S1010-6030(96)04547-9

[29] Singer, K.D. (1981) Measurements of Molecular Second Order Optical Susceptibilities Using DC Induced Second Harmonic Generation. Journal of Chemical Physics, 75, 3572-3580. https://doi.org/10.1063/1.442467

[30] Dragonetti, C., Colombo, A., Marinotto, D., Righetto, S., Roberto, D., Valore, A., Escadeillas, M., Guerchais, V., Le Bozec, H., Boucekkine, A., et al. (2014) Functionalized Styryl Iridium (III) Complexes as Active Second-Order NLO Chromophores and Building Blocks for SHG Polymeric Films. Journal of Organometallic Chemistry, 751, 568-572. https://doi.org/10.1016/j.jorganchem.2013.09.003

[31] Valore, A., Cariati, E., Dragonetti, C., Righetto, S., Roberto, D., Ugo, R., et al. (2010) Cyclometalated Ir(III) Complexes with Substituted 1,10-Phenanthrolines: A New Class of Efficient Cationic Organometallic Second-Order NLO Chromophores. Chemistry, 16, 4814-4825. https://doi.org/10.1002/chem.200902788

[32] Oudar, J.L. and Chemla, D.S. (1977) Hyperpolarizabilities of the Nitroanilines and Their Relations to the Excited State Dipole Moment. The Journal of Chemical Physics, 66, 2664-2668. https://doi.org/10.1063/1.434213

[33] Oudar, J.L. (1977) Optical Nonlinearities of Conjugated Molecules. Stilbene Derivatives and Highly Polar Aromatic Compounds. The Journal of Chemical Physics, 67, 446-457. https://doi.org/10.1063/1.434888

[34] Colombo, A., et al. (2019) A Highly Luminescent Tetrahydrocurcumin Ir(III) Complex with Remarkable Photoactivated Anticancer Activity. Chemistry. A European Journal, 25, 7948-7952.

[35] Colombo, A., Fontani, M., Dragonetti, C., Roberto, D., Williams, J.A.G., Scotto di Perrotolo, R., Casagrande, F., Barozzi, S. and Polo, S. (2019) A Highly Luminescent 
Tetrahydrocurcumin Ir(III) Complex with Remarkable Photoactivated Anticancer Activity. Chemistry-A European Journal, 25, 7948-7952. https://doi.org/10.1002/chem.201901527

[36] Cariati, E., Roberto, D., Ugo, R., Ford, P.C., Galli, S. and Sironi, A. (2002) X-Ray Structures and Emissive and Second-Order Nonlinear Optical Properties of Two Inorganic-Organic Polymeric Adducts of $\mathrm{CuI}$ with 4-Acetylpyridine. Chemistry of Materials, 14, 5116-5123. https://doi.org/10.1021/cm020640w

[37] Barsu, C., Fortrie, R., Nowika, K., Baldeck, P.L., Vial, J.C., Barsella, A., et al. (2006) Synthesis of Chromophores Combining Second Harmonic Generation and Two Photon Induced Fluorescence Properties. Chemical Communications, 45, 4744-4746. https://doi.org/10.1039/B610557B

[38] Todescato, F., Fortunati, I., Carlotto, S., Ferrante, C., Grisanti, L., Sissa, C., et al. (2011) Dimers of Polar Chromophores in Solution: Role of Excitonic Interactions in One- and Two-Photon Absorption Properties. Physical Chemistry Chemical Physics, 13, 11099-11109. https://doi.org/10.1039/c0cp02736g

[39] Chan, C.K.M., Tao, C.H., Li, K.F., Wong, M.C., Zhu, N., Cheah, K.W., et al. (2011) Synthesis, Characterization, Luminescence and Nonlinear Optical (NLO) Properties of Truxene-Containing Platinum(II) Alkynyl Complexes. Journal of Organometallic Chemistry, 696, 1163-1173. https://doi.org/10.1016/j.jorganchem.2010.09.044

[40] Rossi, E., Colombo, A., Dragonetti, C., Righetto, S., Roberto, D., Ugo, R., Valore, A., Williams, J.A.G., Lobello, M.G., De Angelis, F., et al. (2013) Tuning the Dipolar Second-Order Nonlinear Optical Properties of Cyclometalated Platinum(II) Complexes with Tridentate $\mathrm{N}^{\wedge} \mathrm{C}^{\wedge} \mathrm{N}$ Binding Ligands. Chemistry-A European Journal, 19, 9875-9883. https://doi.org/10.1002/chem.201301131

[41] Chavan, S.S., Pawal, S.B., Lolage, S.R. and Garadkar, K.M. (2017) Synthesis, Spectroscopic Characterization, Luminescence and NLO Properties of Heterometallic $\mathrm{M}(\mathrm{II})-\mathrm{Ru}(\mathrm{II})(\mathrm{M}=\mathrm{Ni}$ and $\mathrm{Zn}$ ) Hybrid Complexes Composed of Coordination and Organometallic Sites. Journal of Organometallic Chemistry, 853, 18-26.

https://doi.org/10.1016/j.jorganchem.2017.10.020

[42] Guerchais, V., Boixel, J. and Bozec, H.L. (2017) Linear and Nonlinear Optical Molecular Switches Based on Photochromic Metal Complexes. Photon-Working Switches. Springer, Berlin. https://doi.org/10.1007/978-4-431-56544-4_18

[43] Zhao, H., Garoni, E., Roisnel, T., Colombo, A., Dragonetti, C., Marinotto, D., Righetto, S., Roberto, D., Jacquemin, D., Boixel, J., et al. (2018) Photochromic DTE-Substituted-1, 3-di(2-pyridyl)benzene Platinum(II) Complexes: Photomodulation of Luminescence and Second-Order Nonlinear Optical Properties. Inorganic Chemistry, 57, 7051-7063. https://doi.org/10.1021/acs.inorgchem.8b00733

[44] Chakrabarty, R., et al. (2018) Multifunctional Lanthanide Complexes: Mesomorphism, Photoluminescence and Second Order NLO Property. ChemistrySelect, 3, 8245-8251.

[45] Matozzo, P., Colombo, A., Dragonetti, C., Righetto, S., Roberto, D., Biagini, P., Fantacci, S. and Marinotto, D. (2020) A Known Chiral Bis(salicylaldiminato)zinc(II) Complex with Unexpected Interesting Second-Order Nonlinear Optical and Luminescent Properties in Solution. Inorganics, 8, 25.

https://doi.org/10.3390/inorganics8040025

[46] Tessore, F., Cariati, E., Cariati, F., Roberto, D., Ugo, R., Mussini, P., et al. (2010) The Role of Ion Pairs in the Second-Order NLO Response of 4-x-1-methylpiridinium Salts. ChemPhysChem, 11, 495-507.

https://doi.org/10.1002/cphc.200900696 
[47] Alain, V., Blanchard-Desce, M., Ledoux-Rak, I. and Zyss, J. (2000) Amphiphilic Polyenic Push-Pull Chromophores for Nonlinear Optical Applications. Chemical Communications, 5, 353-354. https://doi.org/10.1039/a908717f

[48] Dragonetti, C., Righetto, S., Roberto, D., Valore, A., Benincori, T., Sannicolo, F., et al. (2009) Cationic Cyclometallated Iridium(III) Complexes with Substituted 1,10-Phenanthrolines: The Role of the Cyclometallated Moiety on This New Class of Complexes with Interesting Luminescent and Second Order Non Linear Optical Properties. Journal of Materials Science Materials in Electronics, 20, 460-464. https://doi.org/10.1007/s10854-008-9670-9

[49] Powell, C.E., Cifuentes, M.P., Morrall, J.P., Stranger, R., Humphrey, M.G., Samoc, M., et al. (2003) Organometallic Complexes for Nonlinear Optics. 30.1 Electrochromic Linear and Nonlinear Optical Properties of Alkynylbis(diphosphine)ruthenium Complexes. Journal of the American Chemical Society, 125, 602-610.

https://doi.org/10.1021/ja0277125

[50] Dragonetti, C., Righetto, S., Roberto, D., et al. (2007) Cyclometalated Iridium(III) Complexes with Substituted 1,10-Phenanthrolines: A New Class of Highly Active Organometallic Second Order NLO-Phores with Excellent Transparency with Respect to Second Harmonic Emission. Chemical Communications, 40, 4116-4118. https://doi.org/10.1039/b708073e

[51] Dragonetti, C., Falciola, L., Mussini, P., et al. (2007) The Role of Substituents on Functionalized 1,10-Phenanthroline in Controlling the Emission Properties of Cationic Iridium(III) Complexes of Interest for Electroluminescent Devices. Inorganic Chemistry, 46, 8533-8547. https://doi.org/10.1021/ic700414z

[52] Ledoux, I. and Zyss, J. (1982) Influence of the Molecular Environment in Solution Measurements of the Second-Order Optical Susceptibility for Urea and Derivatives. Chemical Physics, 73, 203-213. https://doi.org/10.1016/0301-0104(82)85161-6

[53] Dragonetti, C., Righetto, S., Roberto, D., et al. (2009) Cationic Cyclometallated Iridium(III) Complexes with Substituted 1,10-Phenanthrolines: The Role of the Cyclometallated Moiety on This New Class of Complexes with Interesting Luminescent and Second Order Non Linear Optical Properties. Journal of Materials Science: Materials in Electronics, 20, 460-464. https://doi.org/10.1007/s10854-008-9670-9 